Revista de la red interuniversitaria de estudios sobre las literaturas rioplatenses contemporáneas en Francia

$18 \mid 2018$

El río y la ciudad

\title{
Un paseo, una colección
}

\section{Guillermo Mondejar}

URL: http://journals.openedition.org/lirico/5681

DOI: $10.4000 /$ lirico.5681

ISSN: 2262-8339

Editor

Réseau interuniversitaire d'étude des littératures contemporaines du Río de la Plata

\section{Referencia electrónica}

Guillermo Mondejar, « Un paseo, una colección», Cuadernos LIRICO [En línea], 18 | 2018, Puesto en

línea el 13 octubre 2018, consultado el 03 mayo 2019. URL : http://journals.openedition.org/

lirico/5681 : DOl : 10.4000/lirico.5681

Este documento fue generado automáticamente el 3 mayo 2019.

\section{(c) (i) (9)}

Cuadernos LIRICO está distribuido bajo una Licencia Creative Commons Atribución-NoComercialSinDerivar 4.0 Internacional. 


\title{
Un paseo, una colección
}

\author{
Guillermo Mondejar
}

\section{NOTA DEL EDITOR}

Este texto fue leído en la presentación de El horizonte fluvial (Sergio Delgado, Alexis Chausovsky y Guillermo Mondejar [eds.], Paraná, EDUNER, col. El País del Sauce", 2017) el viernes 3 de marzo de 2017 en la universidad de Paris 8. Este libro reúne los trabajos de Graciela Silvestri, Edgardo Dobry, Enrique Fernández Domingo, Alexis Chausovsky, Claudia Rosa, Graciela Villanueva, Gustavo Lambruschini y Sergio Delgado que fueron presentados en el marco del coloquio internacional realizado en Paraná, en septiembre de 2015. Participaron de la presentación la mayor parte de los autores. Este texto de Mondejar, concretamente, tenía por objetivo presentar el libro pero también la colección "El país del sauce" a la cual pertenece.

... en mis paseos por la ciudad... siento casi físicamente cómo la corriente del tiempo se desacelera en el campo de gravitación de las cosas olvidadas...

W.G. Sebald, Austerlitz

Desde cubierta, Alcide D'Orbigny celebra encontrar, luego de tanta monotonía, una costa de aspecto tan vivo, y lamenta no poder detenerse para desenterrar las ostras fósiles que le aseguraron esconden esas barrancas. Se fascina con el método de los lugareños para transportar la leña que calentará los hornos de cal: una especie de balsa remolcada por seis caballos que nadan contra corriente. La leña la traen de la isla que está frente a La Bajada. Esta denominación, en feliz decantación toponímica, partiendo de "Baxada de Santa Fe" se despojará de remisiones religiosas y el guaranítico nombre del río inundará el de la ciudad: Paraná. Así se llama esta capital sin acto de fundación que se hermana al mar por este cauce. En sus orillas una potrilla chapotea en la costa, Madariaga aclara que el poeta la dejó pastando y se metió en su casa, no sin antes correr a unos chiquillos que pateaban a un sapo, y agrega que Ortiz ha de estar "empujando las pajas del Paraná hacia el mar". Es que por este río, lo criollo se universaliza. Machete en mano, Reynaldo Ros 
trae noticias de aguas abajo, del delta, y orgulloso comenta de las más de treinta variedades de álamos del vivero experimental. La edad de Paraná, acota Villanueva, se mide por la belleza de sus árboles. Roberto Arlt desembarca de un carguero y exclama: “¡Parece un puerto abierto en el corazón de las sierras!”, luego entra al correo frente al puerto para despachar una carta que contiene un aguafuerte para El Mundo, sale y se dispone a "subir" a la ciudad. Son tantos, que cuenta los escalones: ciento setenta. Un anónimo Rubén Darío desembarca para visitar un amigo y en esta bohemia de provincias escucha discreto mientras disfruta su licor. Se oyen ahora las paletas de un gran barco, dicen que es de una expedición denominada Paraná Ra'anga. En un par doble del Rowing Club baten los remos para alcanzar el hidroavión a Rosario que ya surca el río antes del despegue; solidarios, los remeros, llevan a Nicolás Guillén, quien se demoró entre versos y tragos de despedida y ahora se cuida de no mojar su ejemplar de Crítica y pico. De vacaciones, Edward Young Haslam se maravilla de Paraná y escribe para el diario irlandés The Southern Cross: "el escenario es encantador, con el río lejos hacia abajo y la maleza arriba". Su bisnieto, Jorge Luis Borges, caminando hacia la Biblioteca Popular de Paraná para brindar una conferencia rememora sus ancestros y los paisajes por ellos admirados. Darwin sigue excavando las barrancas y encuentra que "esta sección vertical nos habla claramente de una bahía de pura agua salada, gradualmente robada al mar y convertida al fin en el lecho de un estuario cenagoso, al que fueron arrastrados los cadáveres flotantes". Carga su mochila de numerosas conchas marinas, encuentra dientes de tiburón, toxodon y mastodonte, y el esqueleto de una especie de armadillo gigante. Pero el descubrimiento que más celebra es un diente de caballo porque gracias a él puede concluir que "es un hecho maravilloso en la historia de los mamíferos que en Sudamérica haya vivido y desaparecido un caballo indígena", antiguo emigrante de la Siberia. A pocos pasos Oscar Edelstein y Juan L. Ortiz sintonizan la radio Motorola Transoceánica y discurren junto al río entre músicas e interferencias. Con traje de brin y sombrero panamá, el general Sarmiento desembarca en el puerto y al ver la comitiva de recepción vestida con jaqué negro, exclama: “¿Cómo soportan ese traje en un día de calor como el de hoy?". Visita la Escuela Normal porque ha venido a ver "una obra en marcha" y da su discurso a los alumnos luego de una clase de gimnasia: "una cultura física los distingue del hombre primitivo, yo no tuve la suerte de vosotros", dice mientras hace la mímica de un orangután. En la siesta soleada, con sus camisas mojadas de sudor, Juan José Saer y Hugo Gola trepan la barranca. Allá arriba, como tantas veces, Amaro y Juan se sonríen en silencio al contemplar el banco de arena que emerge frente a la ciudad: uno ve asomar el nuevo mundo, el otro reacciona frente al incipiente desierto. En la calle se cruzan Juan María Gutiérrez y José Hernández; el primero, ministro de Relaciones Exteriores de la Confederación Argentina, viene de reunirse con el presidente Urquiza y lleva la preocupación de convencer al cuerpo diplomático extranjero -que está cómodo en Buenos Aires- de radicarse en Paraná; el segundo, más despreocupado, se dirige al Senado a cumplir sus funciones de taquígrafo. En la Parrilla Oliva un nutrido grupo de artistas y bohemios funda la "República de Puerto Viejo", proclamando presidente al pintor italiano Manuel Marchese y otorgándole el título de "Restaurador de los paisajes naturales". Laurita Bonaparte interrumpe su paseo por la costanera para dirigirse al sindicato: organizan una huelga en Gath y Chaves. Como preparativo para su viaje a Misiones y convaleciente de fiebre tifoidea, Eduardo Ladislao Holmberg se instala en el hotel del puerto. Advierte el avance de la ciencia y el espíritu en la región al descubrir que el Museo de Entre Ríos comenzó en lo que era un reñidero de gallos; conoce a su fundador, Pedro Scalabrini, y destaca que la didáctica de este eminente profesor se sustenta en 
hechos y no en memorizaciones inconducentes: "ha hallado un vasto campo en la Naturaleza misma y removiendo los yacimientos terciarios que parecen el corte de un libro en las barrancas, abre sus hojas en presencia de sus discípulos".

Voy a jugar al Parque Urquiza con mi hijo. Han excavado un sector de la barranca para una remodelación y vemos relucir lo que parecen cascotes blancos en la tierra removida. Escarbamos con nuestras manos y llenamos la mochila de Teo con fósiles marinos. Siento casi físicamente cómo la corriente del tiempo se desacelera... Millones de años en nuestras manos: tomamos el fósil de una concha marina de casi veinte centímetros, aparentan componerla capas, hojas geológicas, como a las barrancas, testimonios acumulados de sucesos fortuitos y deliberados en armonía. Parece un libro.

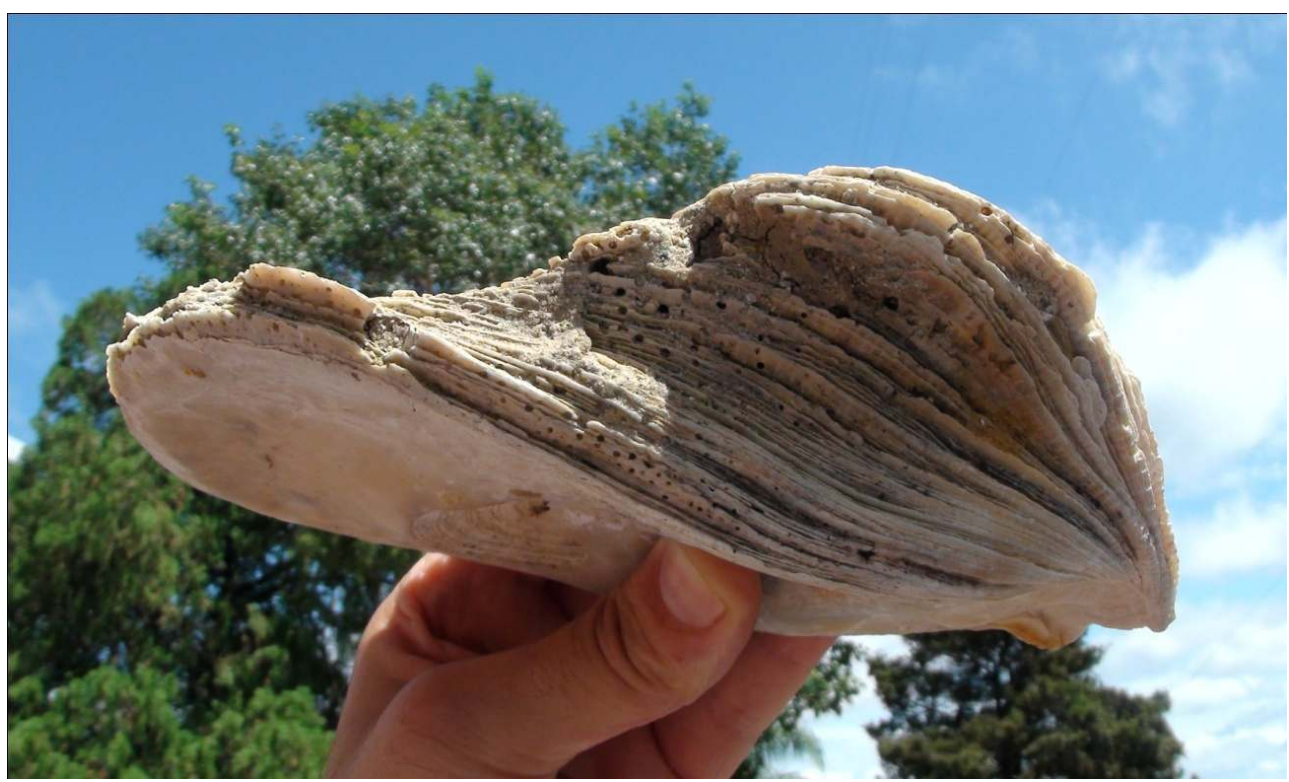

\section{2}

Me doy cuenta de que todas estas presencias de Paraná, ciudad en la que se encuentra la Editorial de la Universidad Nacional de Entre Ríos (EDUNER), son sedimentos que esperan ser desenterrados, aunque surgen fácilmente a la vista, en ese paseo real que hice con mi hijo y en ese paseo más bien atemporal de la lectura: las citas coleccionadas pertenecen a nuestros libros. Esa profunda historia, ese sentido universalista y libertario de esta ciudad, que fue capital del país y centro de cultura y ciencia, hoy es algo más bien olvidado, oculto o, mejor dicho, marginal.

Una digresión, otro paseo. A fines del año pasado aparecieron estos afiches en la ciudad y considero que fue, aunque módico, todo un acontecimiento. Como puede verse, ocupan el espacio público con referencias culturales (pienso en la alusión al poema "Fui al río..." de Juan L. Ortiz, que termina con este verso: “Me atravesaba un río...") y sociales que nos 
interpelan. Se imprimen sobre la propaganda religiosa y contra la apatía y el conservadurismo paranaense.

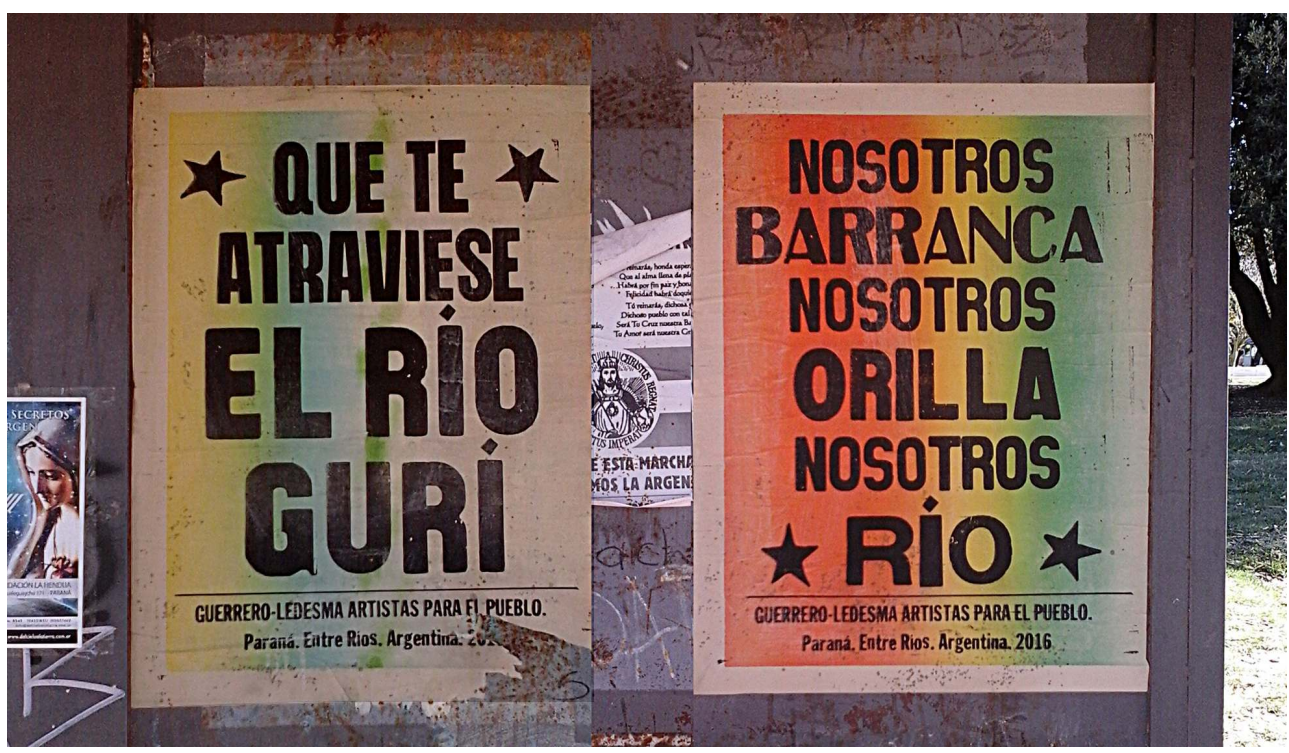

\section{4}

Este carácter conservador de la ciudad lo notamos en los intentos de erigir hitos urbanos. Estas son algunas de las últimas intervenciones en el espacio público junto al río: instalación de un avión que participó en la guerra de Malvinas; un mástil gigante (de 55 metros de altura, con una bandera de $25 \times 10$ ) y un proyecto del arzobispado de construir una cruz de cemento macizo de casi 50 metros de alto. Todos signos de los tradicionales poderes fácticos.

En realidad, Paraná no tiene un hito urbano puntual: un puente, una torre, un obelisco. El hito urbano que identifica a Paraná es el Parque Urquiza. Es un espacio que hace de interfaz entre la ciudad y el río, que todos quienes vivimos allí lo sentimos con orgullo y es la mejor bienvenida y ofrecimiento que hace la ciudad a los visitantes. Y aquí me interesa superponer dos imágenes de la ciudad, separadas por un siglo de distancia.

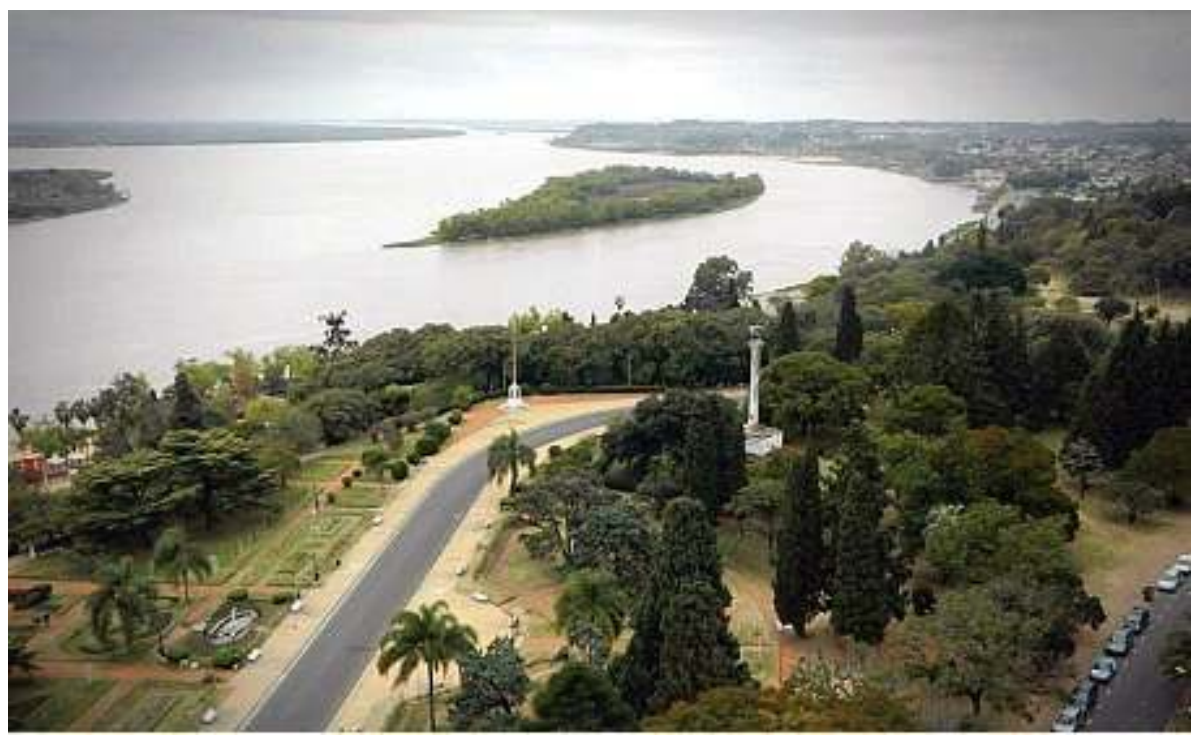


El Parque Urquiza es un parque de diseño proyectado sobre un despeñadero hacia el río, es decir, es la modulación armoniosa de senderos sobre una barranca abrupta. El proyecto es de principios del siglo XX y pertenece al paisajista parisino Jules Charles Thays, que diseñó muchos parques emblemáticos de la Argentina.

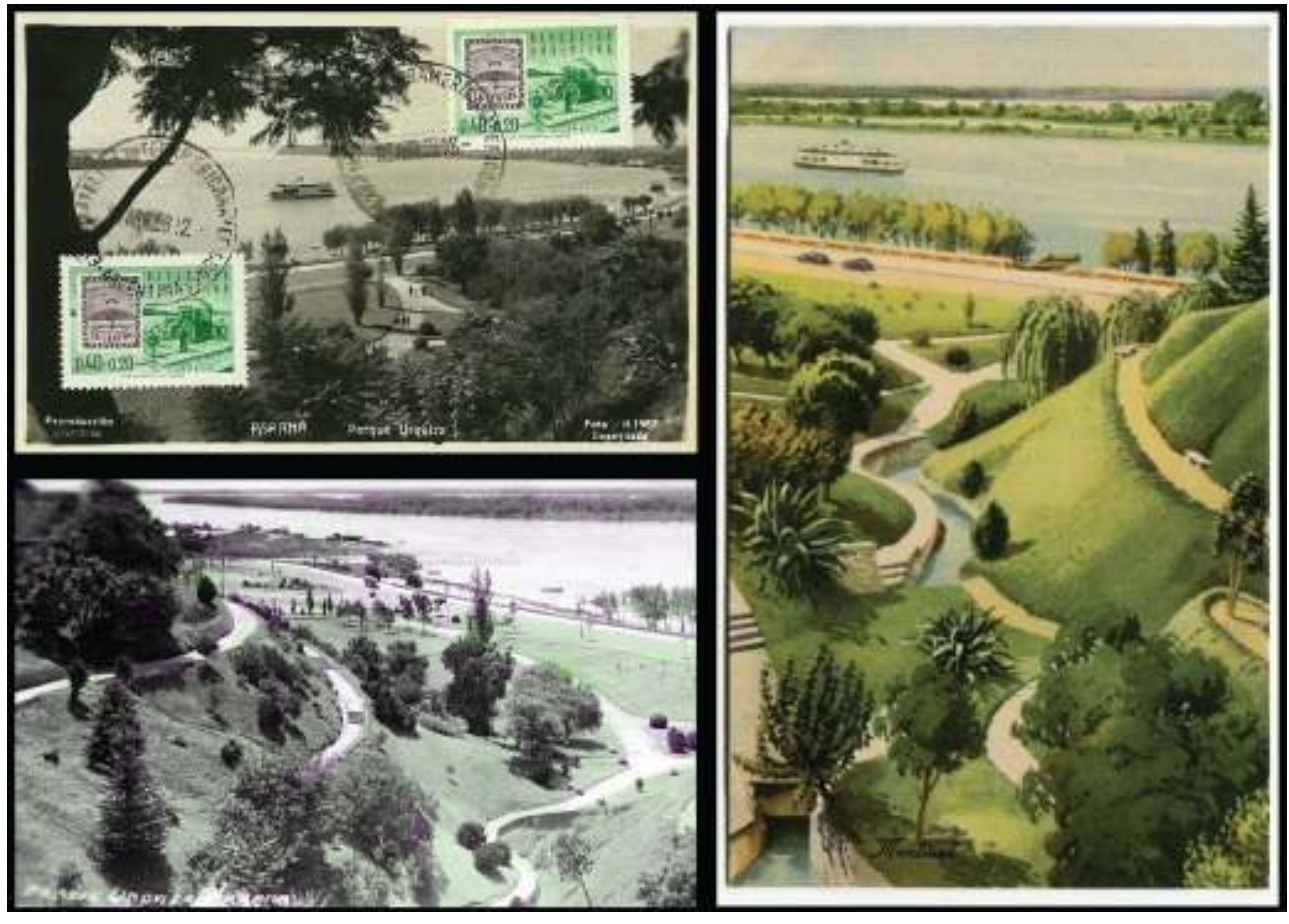

Un detalle para nada secundario es que su construcción se realizó durante la crisis del 30, y las autoridades del Estado y algunos empresarios locales tomaron decisiones pensando que la mejor forma de enfrentarla era proyectando una metrópolis moderna. En 1932 se formó una Comisión de Ayuda a los Desocupados, muchos seguramente vivían en el rancherío de la costa, y a su mano de obra debemos la construcción del Parque Urquiza.

Casi 100 años después, algunas de las obras más importantes sobre el río son barrios privados. Por ejemplo, de manera fraudulenta, en una evidente complicidad privada/ estatal, un empresario se quedó con lo que fuera el mejor balneario público: "Los Arenales". El terreno está dentro del ejido de la ciudad sobre el río Paraná, ubicado de la "línea de ribera" hacia el río. 


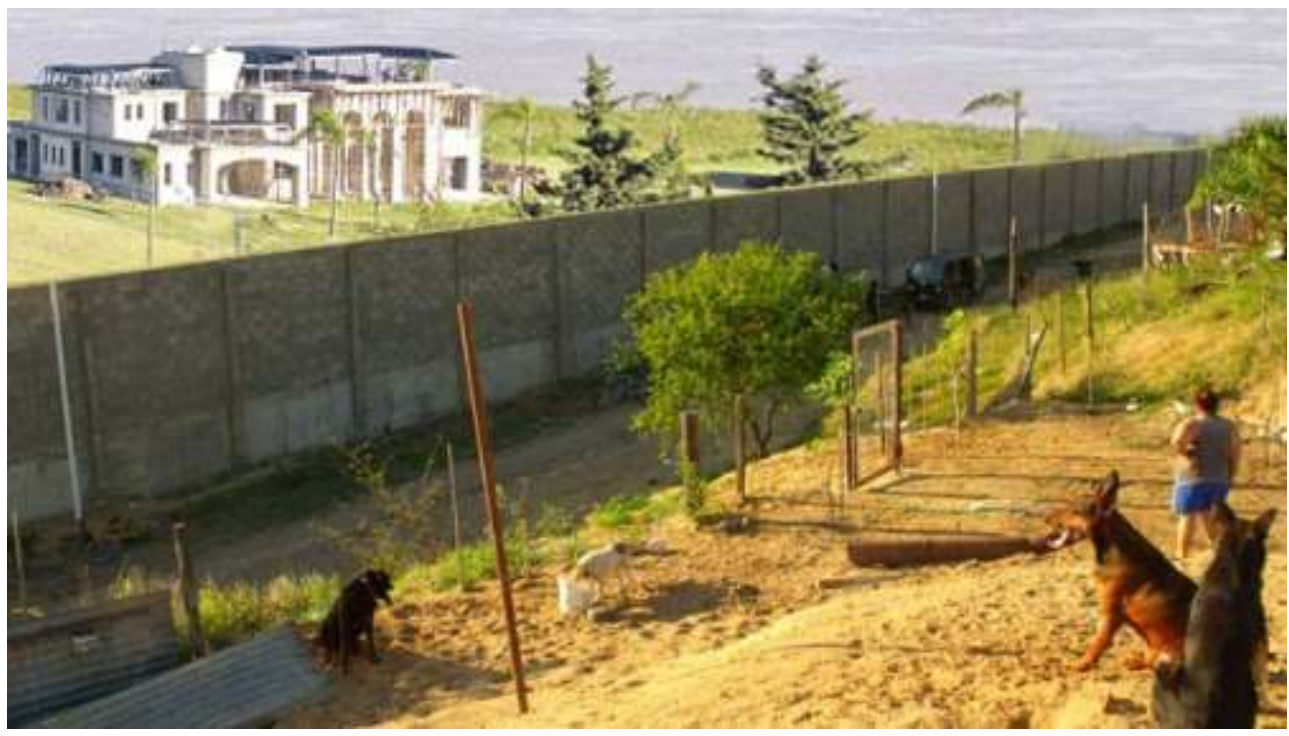

Siendo parte del dominio público, los terrenos ribereños son inalienables y están fuera del comercio, pero irregularmente cayeron en manos privadas. Aquí podemos ver la división de lotes, vendidos y disponibles.

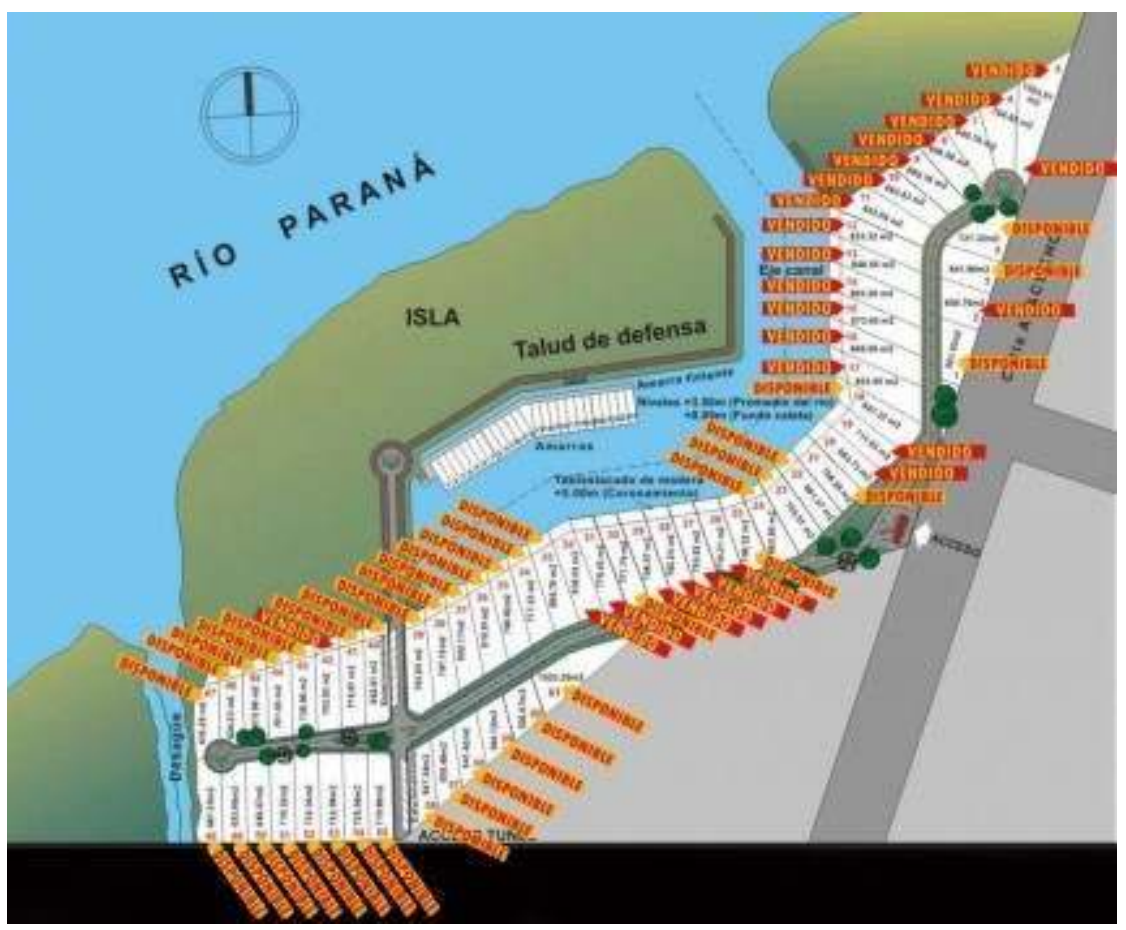

Conclusión. Hace cien años, el Estado, con ayuda de la iniciativa privada y popular, realizaba la mayor obra en terrenos de uso público que fortalece la identidad de Paraná como ciudad ribereña: el Parque Urquiza. Hoy, un murallón en un sector ribereño impide el acceso y la visual al río de los vecinos. Tras la muralla se construye un barrio privado y exclusivo de 62 lotes y amarras. 


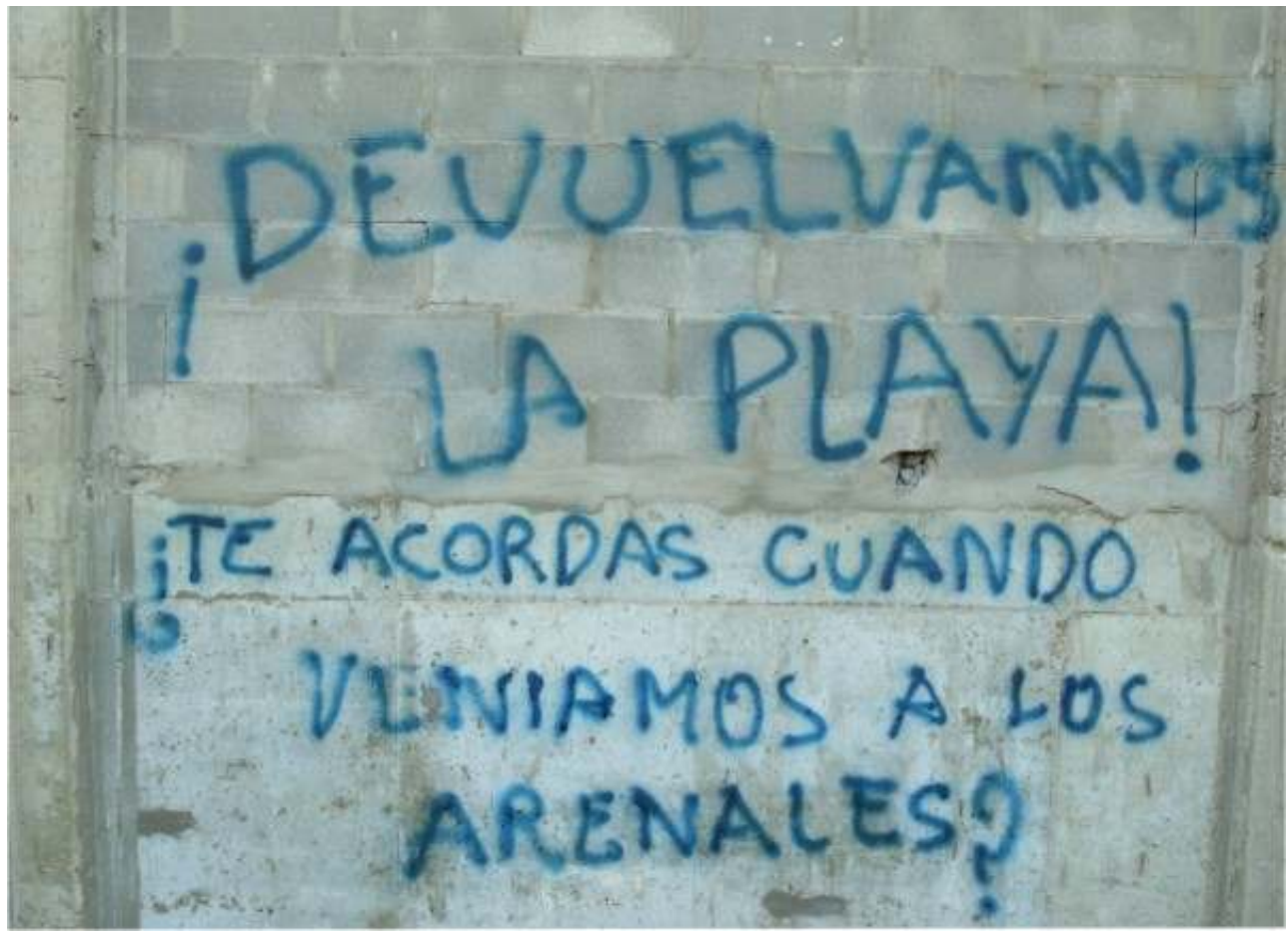

\section{5}

Podemos decir que aquí hay un motivo que enlaza nuestra tarea editorial, la colección El País del Sauce, el coloquio realizado en Paraná sobre El horizonte fluvial y este del que hoy participamos sobre El río y la ciudad.

Con nuestras ediciones, desde una universidad pública, de alguna manera defendemos un lugar, defendemos un paisaje. En este caso el de Paraná, la llamada "ciudad-paisaje", que de manera paradigmática pone en escena estas relaciones entre libro, ciudad y río. Pero también, por extensión, el de toda una región que se desarrolla "entre ríos", el Paraná y el Uruguay, también llamada el "Litoral".

\section{6}

A mediados del 2000, EDUNER comenzó una nueva etapa y el primer libro literario publicado fueron los Cuentos completos de Juan José Manauta, a fines de 2006. La edición de la obra de Manauta, además de significar un justo reconocimiento a un escritor que estaba olvidado en los "círculos literarios", para nuestra editorial era una carta de presentación. A partir de esta edición abrimos un diálogo para definir las características que debía tener el proyecto editorial de nuestra universidad. Luego de enviar un ejemplar a París, el 4 de mayo de 2007 recibimos esta comunicación de Sergio Delgado:

Esta es la línea que debe trabajar una universidad, es decir, hacer lo que no hacen las grandes editoriales en Argentina, concentradas en el rendimiento. Algunas observaciones: el aparato crítico que acompaña la edición me parece pobre. No estoy pensando en trabajos estrictamente académicos, sino en textos de divulgación de ideas, de informaciones, que acompañen al lector (tan maltratado por lo general) y que sitúen al escritor en un contexto de lectura. Creo que este es otro punto donde una universidad debe marcar la diferencia con el mercado. [Otra] 
observación: me parece que el lujo es desproporcionado. Me refiero sobre todo a la encuadernación en tapa dura, a la utilización del color en el interior y otras veleidades. Yo sé que es importante que las editoriales universitarias ofrezcan un producto digno, profesional, marcando el presente y el futuro. Pero esto se puede hacer sin ostentación. [Quizás] se trata de detalles. $O$ en todo caso de algo muy de fondo: la necesidad de una coherencia en el trabajo de la universidad, la propuesta de un proyecto editorial claro, la programación de colecciones, la constitución de un fondo. Esto hacían las editoriales argentinas y han dejado de hacerlo. Personalmente, no me resigno...

Estas críticas constituyeron, en cierto modo, la "piedra angular" de nuestro plan editorial (la obra de Manauta encontraría más adelante su reivindicación, en una segunda edición ampliada y comentada). El paso siguiente, trabajando juntos, fue formar un equipo editorial y así asumimos la edición de las Obras completas de Amaro Villanueva. Es importante destacar esta obra porque, como se dice en la introducción de El horizonte fluvial, "por sus características y desafíos, constituyó una base de datos, una toma de conciencia y al mismo tiempo un estímulo frente a estos problemas de nuestra cultura". Si tomamos estos tres volúmenes, publicados en abril de 2010, se advierte que allí se despliegan la mayoría de las aristas de un plan de edición, de alguna manera sentó las bases del proceso de investigación en archivos; la convocatoria y armonización de un equipo de colaboradores diverso, para asegurar un aparato crítico que actualice la lectura de la obra; y la selección y elaboración de materiales anexos, documentales y visuales, cronologías, bibliografías, notas. Aquí se perfiló la estructura de los libros que proponemos.

Luego de la edición de las obras completas de Villanueva ya estábamos preparados para el desarrollo de una colección, y así nació El País del Sauce, que con casi una docena de libros publicados y otros tantos en desarrollo constituye en cierta forma el alma de nuestro plan editorial en el campo cultural.

El País del Sauce propone pensar, desde una concepción dinámica y plural, nuestra región. Testimonia esta apertura la diversidad de los autores y la diversidad de los colaboradores y responsables de los volúmenes: escritores, lectores, científicos, poetas, universitarios, autodidactas, de todas partes, de todas las edades.

El debate sobre nuestra región está presente desde el primer párrafo del primer borrador de la colección, que data de septiembre de 2010:

Esta colección de libros (que por el momento llamamos "Río Paraná" y/o "La Mesopotamia argentina" y/o "Litoral") debe edificarse sobre el concepto de "región cultural". El concepto de "región", muy maltratado por un pensamiento conservador, reduccionista, que se apropia del mismo como de una bandera, se construye por lo general, al menos en sus modalidades más emblemáticas, buscando la diferencia (por ejemplo, en oposición a la metrópolis) y no la identidad; este concepto tiene que volver a ser definido. $O$, si se quiere, tiene que ser inventado.

Así se sintetiza esta idea en la introducción del libro El horizonte fluvial: "Nuestro país necesita descentralizarse y diversificarse, pero asumiendo el desafío universal del color local". Esta introducción, disponible on line, es en cierta forma una memoria de El País del Sauce, hace un balance de lo hecho y abre los desafíos para el futuro:

https://eduner.uner.edu.ar/public/attached/690190079289.INDICE\%20Y\%

20FRAGMENTOS.pdf

Nuestro catálogo cultural se completa con otras tres colecciones, dos ya en curso y otra, proyectada para el futuro, destinada a autores contemporáneos. Las dos primeras son: 
Tierra de Letras: libros gruesos, a veces en varios volúmenes, donde se editan obras "completas", reunidas por primera vez. Puede tratarse del conjunto de la obra, como es el caso de Amaro Villanueva o Francisco Madariaga, o de una parte genérica, como los ya mencionados cuentos de Juan José Manauta o el teatro de Arnaldo Calveyra.

Cuadernos de las Orillas: pequeños libros especiales con textos casi desconocidos, que surgen "desde las orillas" de otros proyectos más importantes (o, mejor dicho, de mayor envergadura), desde las orillas de la red de la amistad editorial que vamos construyendo. Encontramos en esta colección desde traducciones de Juan L. Ortiz de una escritora francesa hasta la secreta poesía de Adolfo Prieto.

Como decíamos, al menos es una expresión de deseo, el trabajo en "El País del Sauce" es una suerte de hilo secreto que vincula todas las colecciones, dándole coherencia al conjunto.

Desde la aparición del primer libro de la colección, Viaje a Misiones, de Eduardo L. Holmberg, en 2012, el proyecto editorial tuvo su continuación natural en jornadas de trabajo y discusión, primero de manera íntima, con el equipo editorial y los colaboradores que tenían bajo su responsabilidad algún volumen, poniendo en común los distintos proyectos en curso; luego se amplió a coloquios abiertos, como al que hoy asistimos. Del primer coloquio, en 2015, surgió el libro que hoy presentamos, la última novedad de la colección: El horizonte fluvial. De alguna manera esta obra testimonia la sinergia establecida entre el proyecto editorial y los intercambios y debates producidos en los encuentros. El volumen lleva un texto de introducción redactado principalmente por Sergio Delgado, pero construido, escrito, por todo el equipo editorial, de allí la firma colectiva. Cito un fragmento porque allí se sintetizan los alcances de la colección El País del Sauce:

La colección es un proyecto en construcción y su dinámica de trabajo exigió desde el principio, lo exige todavía y deberá exigirlo en el futuro si desea conservar su salud, el encuentro con diversos interlocutores: autores, investigadores, editores, lectores. Se sitúa así, no sin dificultad, en una encrucijada de perspectivas y miradas. Su nombre, El País del Sauce, se inspira en un verso de Juan L. Ortiz, del poema "Entre Ríos" de El junco y la corriente. El poeta identifica su país con el sauce y reflexiona sobre la característica del objeto contemplado: árbol que se aferra a la tierra pero que, como suele encontrarse en las orillas, tiene un por lo menos flexible significado fluvial. [...] La pregunta por un "país del sauce", que vuelve una y otra vez en las ponencias y las conversaciones de este libro, implica entonces la búsqueda de una imagen y la asunción, en consecuencia, de su desafío.

En segundo lugar hay que decir que esta colección reúne libros sobre la región cultural de las cuencas de los ríos Paraná y Uruguay. Esto implica, somos conscientes, el descuido de los límites habituales de la geografía política, nacional o provincial: se incluyen obras de autores de distintas provincias y de distintos países, siempre y cuando hayan participado, por sus preocupaciones, sus temas o sus motivos, pero sobre todo por la calidad e intensidad de su trabajo, en el diseño de una concepción dinámica de la cultura regional. [...]

El País del Sauce, finalmente, se propone como una colección de libros clásicos. Consideramos que un "clásico" es un libro indispensable, cuyo hallazgo marca la vida de su lector y cuya protección y cuidado compromete a todo un pueblo. Un clásico, entonces, en la encrucijada entre lo individual y lo social, es un texto que se lee desde el presente y no deja de tener actualidad.

Los libros se completan, o en realidad inician su verdadero camino, con el encuentro de un lector, o de una comunidad de lectores, pero ¿qué es un lector? En este paseo editorial 
surgen con espontaneidad las palabras de Adolfo Prieto en su ensayo "La literatura argentina y su público":

Un lector real es un cómplice, el término obligado de un diálogo, la respuesta necesaria al llamado del autor. En una definición extrema, el lector modifica su estructura espiritual al contacto de un libro, cambia de alguna manera, no es, no puede ser el mismo antes y después de la experiencia literaria. El libro crea una necesidad de diálogo que puede ser satisfecha fundamentalmente con el libro, y el lector real, el que padece la urgencia de ese diálogo, busca el libro, lo localiza, lo lee, se funde en él. Un conjunto de lectores semejantes constituye el público real, la caja de resonancia indispensable de toda literatura.

Pasear. Ir al paso, de un lugar a otro, del pasado al porvenir, a veces azorados al marcar cada pisada en un inefable acontecer. En este desafío de la geografía, asumiendo una mirada regional y nacional, no parece haber mejor manera que terminar el paseo de la mano de aquel niño que al abandonar el territorio ruso, escucha estas palabras de su padre: "Míralo bien; no verás cosacos en la Argentina. La Argentina, niño mío, es un país libre". Aquel niño, Abraham ben Gershon Gerchunoff, ya como Alberto, escribirá en Entre Ríos, mi país, otro de los libros de El País del Sauce:

El viajero que recorre Entre Ríos encuentra en la más diminuta aglomeración de casas la sala pública de lectura. Esos anaqueles cargados de volúmenes denuncian la abundancia del lector. Los lomos raídos, las páginas fatigadas, atestiguan la curiosidad del vecindario por lo que se escribe en el país, por lo que se produce en las sedes ilustres de la cultura. El libro circula en Entre Ríos. El agricultor [...] tiene en sus habitaciones, en la repisa que ha fabricado en invierno, [...] la novela de esparcimiento, la obra que resume para su inteligencia ocupada los conocimientos útiles. La biblioteca no es en Entre Ríos un detalle decorativo de la organización comunal, sino un instrumento activo.

Este libro es la historia de la formación de un escritor, en la lectura y en su identidad. Gerchunoff encontró en Argentina la posibilidad de una Nación. Quizás esta utopía se ha ido desgranando en un país que no encuentra el remedio, la ética, que suture las heridas que se empeñan en alejar la justicia y la libertad, pero la utopía sigue siendo un motivo, por ejemplo, para la edición de una colección; el escritor sembró sin éxito, es cierto, pero en los libros late un país posible. Libros, que como las colinas y el cincelado de las barrancas, modulan esta relación del río, la ciudad y, con ellos, nuestras miradas.

Paraná, febrero de 2017

\section{AUTOR}

\section{GUILLERMO MONDEJAR}

Universidad Nacional de Entre Ríos, EDUNER

guillermo.mondejar@gmail.com 